\title{
Trends and Inpatient Outcomes of Venous Thromboembolism-Related Admissions in Patients with Philadelphia-Negative Myeloproliferative Neoplasms
}

\author{
Vatsala Katiyar ${ }^{10}$ Alok Uprety ${ }^{1}$ Andres Mendez-Hernandez ${ }^{1}$ Harry E. Fuentes ${ }^{2}$ () \\ Xavier A. Andrade ${ }^{1}$ Maryam Zia ${ }^{3}$ \\ ${ }^{1}$ Department of Medicine, John H. Stroger Jr. Hospital of Cook County, \\ Chicago, Illinois, United States \\ 2 Department of Hematology and Oncology, Mayo Clinic, Rochester, \\ Minnesota, United States

\begin{abstract}
Address for correspondence Vatsala Katiyar, MD, Department of Medicine, John H. Stroger Jr. Hospital of Cook County, 1969 West Ogden Avenue, Chicago, IL 60612, United States (e-mail: vatsala.katiyar@cookcountyhhs.org).
\end{abstract}

${ }^{3}$ Department of Hematology and Oncology, John H. Stroger Jr.

Hospital of Cook County, Chicago, Illinois, United States

TH Open 2019;3:e203-e209.

\begin{abstract}
Keywords

- venous thromboembolism

- myeloproliferative neoplasm

- polycythemia vera

- essential thrombocytosis

- primary myelofibrosis

Background Patients with Philadelphia-negative myeloproliferative neoplasms (MPNs), including polycythemia vera (PV), essential thrombocytosis (ET), and primary myelofibrosis (MF), have a significant risk of venous thromboembolism (VTE). We aim to determine the trends in annual rates of VTE-related admissions, associated cost, length of stay (LOS), and in-hospital mortality in patients with MPN.

Methods We identified patients with PV, ET, and MF from the Nationwide Inpatient Sample (NIS) database from 2006 to 2014 using ICD-9CM coding. Hospitalizations where VTE was among the top-three diagnoses were considered VTE-related. We compared in-hospital outcomes between VTE and non-VTE hospitalizations using chisquare and Mann-Whitney U-test and used linear regression for trend analysis.

Results We identified 1,046,666 admissions with a diagnosis of MPN. Patients were predominantly white $(65.6 \%)$, females $(52.7 \%)$, with a median age of 66 years (range: 18-108). The predominant MPN was ET (54\%). There was no difference in in-hospital mortality between groups (VTE: $3.4 \%$ vs. non-VTE: $3.2 \% ; p=0.12$ ); however, VTE admissions had a longer LOS (median: 6 vs. 5 days; $p<0.01$ ) and higher cost (median: VTE US\$32,239 vs. 28,$403 ; p \leq 0.01)$.

The annual rate of VTE admissions decreased over time (2006: 3.94\% vs. 2014: 2.43\%; $p \leq 0.01)$, compared with non-VTE-related admissions.

Conclusion In our study, VTE-related admissions had similar in-hospital mortality as compared with non-VTE-related admissions. The rates of hospitalizations due to VTE have decreased over time but are associated with a higher cost and LOS. Newer risk assessment tools may assist in preventing VTE in high-risk patients and optimizing resource utilization.
\end{abstract}

(1) Vatsala Katiyar's ORCID is https://orcid.org/0000-0001-6004-5217.

(D) Harry E. Fuentes's ORCID is https://orcid.org/0000-0002-7837-8359.

received

December 31, 2018

accepted

May 17, 2019
DOI https://doi.org/

10.1055/s-0039-1692988. ISSN 2512-9465. (c) 2019 Georg Thieme Verlag KG Stuttgart · New York
License terms

(c) (1) 


\section{Introduction}

Philadelphia-negative myeloproliferative neoplasms (MPNs) are highly prevalent hematological malignancies that include polycythemia vera (PV), essential thrombocytosis (ET), and primary myelofibrosis (PMF). ${ }^{1,2}$ These malignancies have been associated with a higher risk of venous thromboembolism (VTE) compared with the general population, leading up to one-third of patients with MPN experiencing VTE at any point in their disease. ${ }^{3-5}$ The higher incidence of VTE in patients with MPN has led to development of recommendations of riskadapted strategies to decrease their thromboembolism rate. ${ }^{6}$

Despite risk-adapted preventive strategies, VTE remains one of the leading causes of death and healthcare expenditure in patients with cancer. ${ }^{7-9}$ For instance, in a recent systematic review by Grosse et al, VTE had an estimated incremental cost of $\$ 12,000$ to 15,000 (2014 U.S. dollars [USD]) per patient for first-VTE survivors and complications were estimated to increase cumulative costs up to $\$ 18,000$ to 23,000 ; adding up to a total annual cost of 7 to 10 billion USD to the U.S. healthcare system. ${ }^{10}$ Similarly, Barco et al estimated that VTE has a total annual cost of $€ 1.5$ to 2.2 billion and hospital-associated cost of $€ 1.0$ to 1.5 billion in the European Union. ${ }^{11}$

Although there is emerging information of overall VTErelated costs, there is paucity of data of MPN-associated VTE mortality and healthcare expenditure in hospitalized patients. In this study, we aim to study annual rates of VTE-related admissions, length of inpatient stay (LOS), its associated cost, and in-hospital mortality in patients with MPN.

\section{Methods}

\section{Study Design and Data Source}

We queried the National Inpatient Sample (NIS) databases from 2006 to 2014 and conducted a retrospective analysis of hospitalizations in patients with Philadelphia-negative MPN. The NIS is a national database administered by the Healthcare Cost and Utilization Project sponsored by the Agency of Healthcare Research and Quality (AHRQ). The NIS consists of a stratified sample of approximately $20 \%$ of discharges from all community hospitals in the United States and provides weighted discharges to allow for national estimates.

\section{Population}

We identified patients aged 18 or above, admitted with a diagnosis of PV, ET, and MF using International Classification of Diseases-Ninth Edition-Clinical Modification (ICD-9-CM) coding. Patients with PV were identified using ICD-9CM codes 238.4; patients with ET were identified using code 238.71; and patients with PMF were identified using codes 238.76 and 289.83 .

\section{Variables}

We obtained patients' baseline characteristics using variables provided by the NIS databases. These included age, gender, race, and healthcare payer.
We defined VTE-related hospitalization as an admission that included a VTE event in the primary discharge diagnosis or the initial two secondary diagnoses. A VTE event was allocated using ICD-9-CM codes 415.11, 415.13, and 415.19 for pulmonary embolism; 451.11, 451.2, 451.81, 453.40, 453.41 , and 453.42 for deep vein thrombosis (DVT) of lower extremity; 453.0 for Budd-Chiari syndrome (BCS); and 451.19, 451.83, 451.84, 451.89, 451.9, 452.0, 453.2, 453.3, $453.8,453.82,453.83,453.84,453.85,453.86,453.87$, $453.88,453.89$, and 453.90 for other types of VTE. Superficial vein thromboses were excluded.

Hospitalization costs were obtained using the total charges reported by hospitals to the NIS database. LOS in days was coded as a continuous variable. In-hospital mortality was coded as a binary variable coded from the discharge disposition of patient reported to the NIS database.

\section{Outcomes}

Our primary outcomes included inpatient mortality, hospitalization cost, and LOS of all VTE-related admissions. In addition, we aimed to measure the trends of the annual rates of VTE-related admissions, cost of hospitalization, LOS, and in-patient mortality.

\section{Statistical Analysis}

We used descriptive statistics to summarize the baseline characteristics of the cohort and subgroups. Continuous variables are expressed as mean and standard deviation (SD) or median and interquartile range (IQR) as appropriate. Categorical variables are expressed as absolute numbers and percentages.

National estimates for the annual rates of VTE-related hospitalizations were made using weights provided by the NIS database. We used simple linear regression to analyze the trends of annual rates of VTE-related hospitalizations and inpatient mortality. We compared the trends in annual cost of hospitalization and LOS between groups using MannWhitney $U$-test. All statistical analyses were performed using SPSS version 22.0 (IBM Corp., Armonk, NY).

\section{Results}

We identified 1,046,666 admissions for patients with Philadelphia-negative MPNs from 2006 to 2014. Patients had a median age of 66 years (IQR: 26 years) and were predominantly Caucasians $(n=686,104 ; 65.6 \%)$ and female ( $n=552,016 ; 52.7 \%)$. The most common MPN type was ET ( $n=565,644 ; 54 \%)$, followed by PV $(n=313,588 ; 30 \%)$ and PMF ( $n=167,434 ; 16 \%)$.

Patients were predominantly over 60 years of age in all the three subgroups: 54.1, 62.9, and 89.9\% in ET, PV, and PMF, respectively. Patients had similar demographic and health insurance payer among all MPN types as detailed in - Tables 1 and 2.

We abstracted 39,124 (3.7\%) VTE-related admissions during the study period. VTE hospitalizations were higher in patients with PV $(n=13,057,4.2 \%)$ followed by ET ( $n=20,520 ; 3.5 \%)$ and PMF ( $n=5,548,3.2 \%$; - Table 2$)$. 
Table 1 Demographic characteristics of cohort by type of hospitalization

\begin{tabular}{|c|c|c|c|}
\hline \multicolumn{2}{|c|}{ Characteristics } & \multirow{2}{*}{$\begin{array}{l}\text { VTE hospitalization } \\
n=39,124\end{array}$} & \multirow{3}{*}{$\begin{array}{l}\text { Non-VTE hospitalization } \\
\boldsymbol{n}=1,007,542 \\
622,265(61.7)\end{array}$} \\
\hline & & & \\
\hline Age & $\geq 60 y-n(\%)$ & $23,084(59)$ & \\
\hline Gender & Female-n (\%) & $21,230(54.3)$ & $530,786(52.7)$ \\
\hline \multirow[t]{6}{*}{ Race } & White-n (\%) & $25,953(75.4)$ & $660,151(73.6)$ \\
\hline & African American-n (\%) & $4,802(13.9)$ & $121,856(13.6)$ \\
\hline & Hispanic-n (\%) & $2,222(6.5)$ & $68,849(7.7)$ \\
\hline & Asian or Pacific Islander-n (\%) & $385(1.1)$ & $18,931(2.1)$ \\
\hline & Native American-n (\%) & $132(0.4)$ & $4,878(0.5)$ \\
\hline & Other-n (\%) & $944(2.7)$ & $22,755(2.5)$ \\
\hline \multirow[t]{6}{*}{ Insurance } & Medicare-n (\%) & $20,310(51.9)$ & $568,699(56.6)$ \\
\hline & Medicaid-n (\%) & $3,948(10.1)$ & $111,371(11.1)$ \\
\hline & Private insurance $-n(\%)$ & $10,967(28.0)$ & $233,965(23.3)$ \\
\hline & Self-pay-n (\%) & $2,288(5.9)$ & $56,268(5.6)$ \\
\hline & No charge $-n(\%)$ & $300(0.8)$ & $6,278(0.6)$ \\
\hline & Other-n (\%) & $1,261(3.2)$ & $29,080(2.9)$ \\
\hline \multirow[t]{3}{*}{ Tumor type } & $\mathrm{PV}-n(\%)$ & $13,057(33.3)$ & $300,531(29.8)$ \\
\hline & $\mathrm{ET}-n(\%)$ & $20,520(52.4)$ & $545,124(54.1)$ \\
\hline & PMF-n (\%) & $5,548(14.1)$ & $161,886(16.1)$ \\
\hline
\end{tabular}

Abbreviations: ET, essential thrombocythemia; MPN, myeloproliferative neoplasms; PMF, primary myelofibrosis; PV, polycythemia vera; VTE, venous thromboembolism.

Table 2 Demographic characteristics of cohort by tumor type

\begin{tabular}{|c|c|c|c|c|}
\hline \multicolumn{2}{|l|}{ Characteristics } & \multicolumn{3}{|l|}{ MPN type } \\
\hline & & \multirow{3}{*}{$\begin{array}{l}\mathrm{PV} \\
\boldsymbol{n}=313,588 \\
197,156(62.9) \\
\end{array}$} & \multirow{3}{*}{$\begin{array}{l}\text { ET } \\
n=565,644 \\
305,972(54.1) \\
\end{array}$} & \multirow{3}{*}{$\begin{array}{l}\text { PMF } \\
\boldsymbol{n}=167,434 \\
142,220(89.9 \%)\end{array}$} \\
\hline & & & & \\
\hline Age & $\geq 60 y-n(\%)$ & & & \\
\hline Gender & Male-n (\%) & $182,482(58.2)$ & $227,978(40.3)$ & $84,149(50.3)$ \\
\hline \multirow[t]{6}{*}{ Race } & White-n (\%) & $222,551(81.1)$ & $343,926(67.9)$ & $119,627(79.5)$ \\
\hline & African American-n (\%) & $22,580(8.2)$ & $89,569(17.7)$ & $14,508(9.6)$ \\
\hline & Hispanic-n (\%) & $16,839(6.1)$ & $45,360(8.9)$ & $8,873(5.9)$ \\
\hline & Asian or Pacific Islander-n (\%) & $4,758(1.7)$ & $11,000(2.2)$ & $3,558(2.4)$ \\
\hline & Native American-n (\%) & $1,369(0.5)$ & $3,165(0.6)$ & $476(0.3)$ \\
\hline & Other-n (\%) & $6,388(2.3)$ & $13,809(2.7)$ & $3,501(2.3)$ \\
\hline \multirow[t]{6}{*}{ Insurance } & Medicare-n (\%) & $180,976(57.8)$ & 281,991 (49.9) & $126,041(75.4)$ \\
\hline & Medicaid-n (\%) & $27,920(8.9)$ & $79,649(14.1)$ & $7,750(4.6)$ \\
\hline & Private insurance- $n$ (\%) & $74,685(23.9)$ & $141,961(25.1)$ & $28,285(16.9)$ \\
\hline & Self-pay-n (\%) & $18,680(6.0)$ & $37,569(6.7)$ & $2,308(1.4)$ \\
\hline & No charge-n (\%) & $1,954(0.6)$ & $4,353(0.8)$ & $271(0.2)$ \\
\hline & Other-n (\%) & $8,737(2.8)$ & $19,092(3.4)$ & $2,512(1.5)$ \\
\hline \multirow[t]{2}{*}{ Type of hospitalization } & Non-VTE related-n (\%) & $301,125(95.8)$ & $545,757(96.5)$ & $162,082(96.8)$ \\
\hline & VTE related-n (\%) & $13,057(4.2)$ & $20,520(3.5)$ & $5,548(3.2)$ \\
\hline
\end{tabular}

Abbreviations: ET, essential thrombocythemia; MPN, myeloproliferative neoplasms; PMF, primary myelofibrosis; PV, polycythemia vera; VTE, venous thromboembolism. 
Table 3 Outcomes by VTE event in the entire cohort

\begin{tabular}{|l|l|l|l|}
\hline Outcomes & $\begin{array}{l}\text { Non-VTE } \\
\text { hospitalization }\end{array}$ & $\begin{array}{l}\text { VTE } \\
\text { hospitalization }\end{array}$ & $p$-Value \\
\hline Mortality-n (\%) & $\begin{array}{l}32,617 \\
(3.2)\end{array}$ & $\begin{array}{l}1,283 \\
(3.3)\end{array}$ & 0.646 \\
\hline $\begin{array}{l}\text { Total cost of } \\
\text { hospitalization } \\
\text { (USD)-median } \\
\text { (IQR) }\end{array}$ & $\begin{array}{l}28,426 \\
(42,572)\end{array}$ & $\begin{array}{l}31,549 \\
(46,097)\end{array}$ & 0.001 \\
\hline $\begin{array}{l}\text { Total length } \\
\text { of stay (days)- } \\
\text { median (IQR) }\end{array}$ & $5(5)$ & $6(6)$ & $<0.001$ \\
\hline
\end{tabular}

Abbreviations: IQR, interquartile range; VTE, venous

thromboembolism.

In our cohort, the overall mortality rate was similar in patients with VTE-related hospitalization compared with nonVTE admissions ( 3.3 vs. $3.2 \% ; p=0.646$ ). Nonetheless, in MPN subgroups, patients with PV had a mortality in VTE-related admissions compared with non-VTE-related admissions (3.5 vs. $3.1 \% ; p=0.009$ ). Mortality was similar among VTE- and non-VTE admissions for patients with ET (2.5 vs. 2.3\%; $p=0.053$ ) and PMF (5.6 vs. $6.6 \% ; p=0.002$ ). The case-fatality rate for VTE-related admissions was $0.12 \%$ ( - Table 3 ).

Overall, patients with a VTE-related hospitalization had a higher median cost of hospitalization (USD 31,549 vs. 28,426; $p=0.001$ ) and longer LOS ( 6 vs. 5 days; $p \leq 0.001$ ) compared with non-VTE hospitalizations. Among VTE admissions, patient with ET had the highest cost (median:
USD 35,703 [IQR $=53,703]$ ) and LOS (median: 6 days [IQR $=7]$ ) compared with PV (median: USD 25,745; median LOS: 5 days $[\mathrm{IQR}=4]$ ) and PMF (median: USD 33,213; median LOS: 6 days [IQR $=7$ ]; - Tables 3 and 4).

Acute DVT was the most common VTE event in patients with PV ( $n=5,731,43.9 \%)$ and PMF ( $n=1824,32.9 \%)$, and PE was more common in patients with ET ( $n=8,733,42.6 \%)$. BCS was the third most common VTE event in all the three MPNs (PV: 4.4\%, ET: 1.2\%, PMF: 7.7\%; -Table 5).

During the study period, there was a trend toward a decreased total VTE-related admissions $(2006=4.18 \%$ vs. $2014=3.53 \% ; \quad p<0.001)$ and increased mortality $(2006=2.77 \%$ vs. $2014=4.94 \% ; p<0.001)$ and costs per hospitalization (2006 = USD 22,702 vs. $2014=$ USD 37,100; $p<0.001)$. Notably, there was a trend toward an increased yearly rate of PE-related admissions $(2006=1.1 \%$ vs. $2014=1.49 \% ; p<0.001)$, PE-related in-hospital mortality $(2006=6.21 \%$ vs. $2014=7.96 \% ; p<0.001)$, and PE hospitalization costs $(2006=$ USD 27,027 vs. $2014=$ USD 42,959; $p \leq 0.001 ;$ - Figs. 1-3).

\section{Discussion}

This retrospective analysis was designed to examine the annual trends in VTE-related hospitalizations among patients with Philadelphia-negative MPNs and their associated cost, LOS, and inpatient mortality.

We studied hospitalizations during the period of 2006 to 2014 in our cohort of MPN patients. From a total of 1,046,666

Table 4 Outcomes of VTE hospitalizations by tumor type

\begin{tabular}{|l|l|l|l|l|l|l|l|l|l|}
\hline \multirow{2}{*}{ Outcomes } & \multicolumn{3}{l}{ PV } & \multicolumn{2}{l|}{ ET } & \multicolumn{2}{l|}{ PMF } & \multicolumn{2}{l|}{$p$-Value } \\
\cline { 2 - 9 } & Non-VTE & VTE & Non-VTE & VTE & Non-VTE & VTE & $\begin{array}{l}\text { PV vs. ET } \\
\text { (VTE vs. VTE) }\end{array}$ & $\begin{array}{l}\text { PV vs. PMF } \\
\text { (VTE vs. VTE) }\end{array}$ & $\begin{array}{l}\text { ET vs. PMF } \\
\text { (VTE vs. VTE) }\end{array}$ \\
\hline Hospitalization & $\begin{array}{l}301,125 \\
(95.8)\end{array}$ & $\begin{array}{l}13,057 \\
(4.2)\end{array}$ & $\begin{array}{l}545,757 \\
(96.5)\end{array}$ & $\begin{array}{l}20,520 \\
(3.5)\end{array}$ & $\begin{array}{l}162,082 \\
(96.8)\end{array}$ & $\begin{array}{l}5,548 \\
(3.2)\end{array}$ & $<0.001$ & $<0.001$ & $<0.001$ \\
\hline Mortality-n (\%) & $\begin{array}{l}9,290 \\
(3.1)\end{array}$ & $\begin{array}{l}457 \\
(3.5)\end{array}$ & $\begin{array}{l}12,633 \\
(2.3)\end{array}$ & $\begin{array}{l}518 \\
(2.5)\end{array}$ & $\begin{array}{l}10,694 \\
(6.6)\end{array}$ & $\begin{array}{l}308 \\
(5.6)\end{array}$ & $<0.001$ & $<0.001$ & $<0.001$ \\
\hline $\begin{array}{l}\text { Total cost of } \\
\text { hospitalization } \\
\begin{array}{l}\text { (USD)-median } \\
\text { (IQR) }\end{array}\end{array}$ & $\begin{array}{l}23,542 \\
(32,083)\end{array}$ & $\begin{array}{l}25,745 \\
(34,962)\end{array}$ & $\begin{array}{l}31,729 \\
(48,947)\end{array}$ & $\begin{array}{l}35,805 \\
(53,703)\end{array}$ & $\begin{array}{l}28,942 \\
(43,096)\end{array}$ & $\begin{array}{l}33,213 \\
(47,337)\end{array}$ & $<0.001$ & $<0.001$ & 0.115 \\
\hline $\begin{array}{l}\text { Total length of stay } \\
\text { (days)-median } \\
\text { (IQR) }\end{array}$ & $4(4)$ & $5(4)$ & $5(7)$ & $6(7)$ & $5(5)$ & $6(7)$ & $<0.001$ & $<0.001$ & 0.300 \\
\end{tabular}

Abbreviations: ET, essential thrombocythemia; PMF, primary myelofibrosis; PV, polycythemia vera; VTE, venous thromboembolism.

Table 5 VTE events per MPN type

\begin{tabular}{|l|l|l|l|l|l|l|}
\hline VTE subtype & PV & ET & PMF & \multicolumn{2}{l|}{$p$-Value } \\
\cline { 4 - 7 } & & & & PV vs. ET & PV vs. PMF & ET vs. PMF \\
\hline Acute DVT-n (\%) & $5,731(43.9 \%)$ & $7,490(36.5 \%)$ & $1,824(32.9 \%)$ & $<0.001$ & $<0.001$ & 0.003 \\
\hline Pulmonary embolism-n (\%) & $4,586(35.1 \%)$ & $8,733(42.6 \%)$ & $1,724(31.1 \%)$ & $<0.001$ & $<0.001$ & $<0.001$ \\
\hline Bud-Chiari syndrome-n (\%) & $568(4.4 \%)$ & $250(1.2 \%)$ & $428(7.7 \%)$ & $<0.001$ & 0.007 & $<0.001$ \\
\hline Other-n (\%) & $2,172(16.6 \%)$ & $4,047(19.7 \%)$ & $1,572(28.3 \%)$ & $<0.001$ & $<0.001$ & $<0.001$ \\
\hline
\end{tabular}

Abbreviations: DVT, deep vein thrombosis; ET, essential thrombocythemia; MPN, myeloproliferative neoplasm; PMF, primary myelofibrosis; PV, polycythemia vera; VTE, venous thromboembolism. 


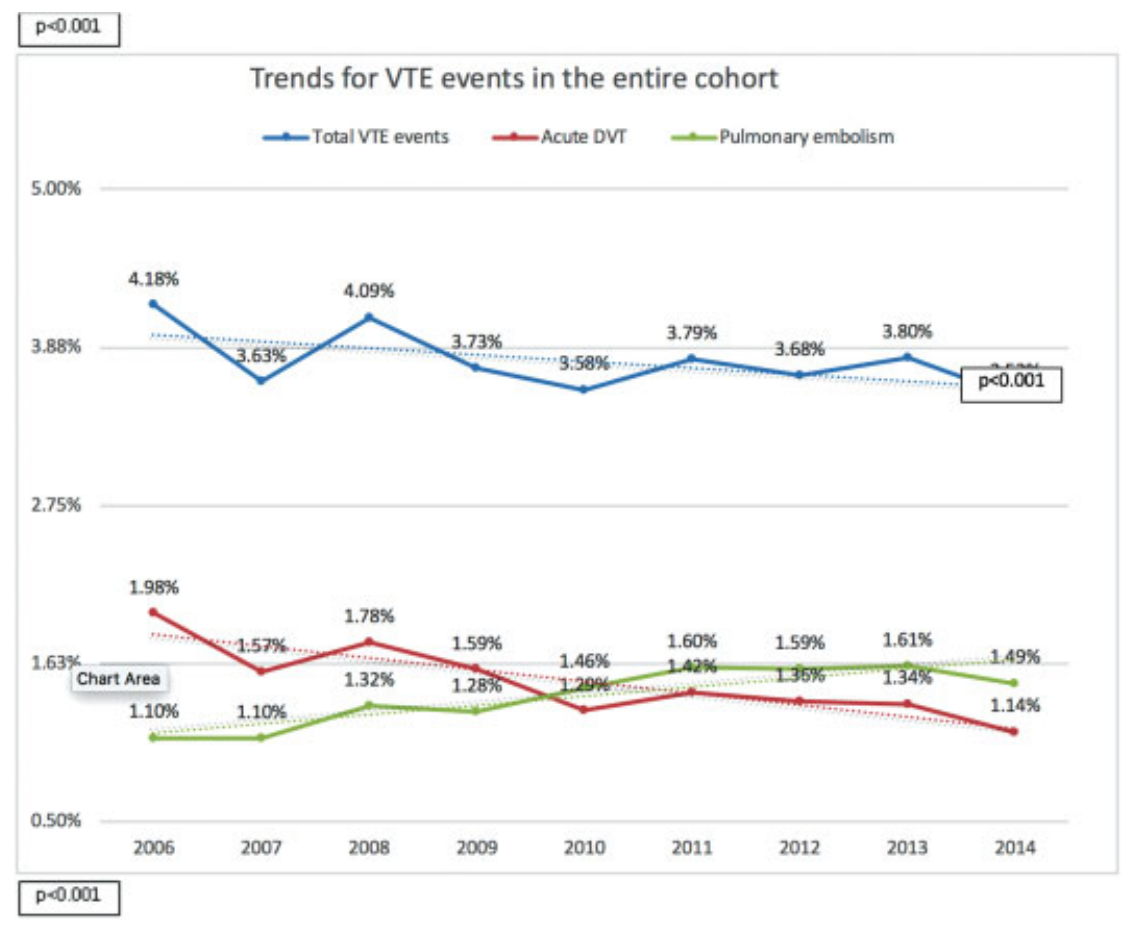

Fig. 1 Trends for VTE events in the entire cohort. VTE, venous thromboembolism.

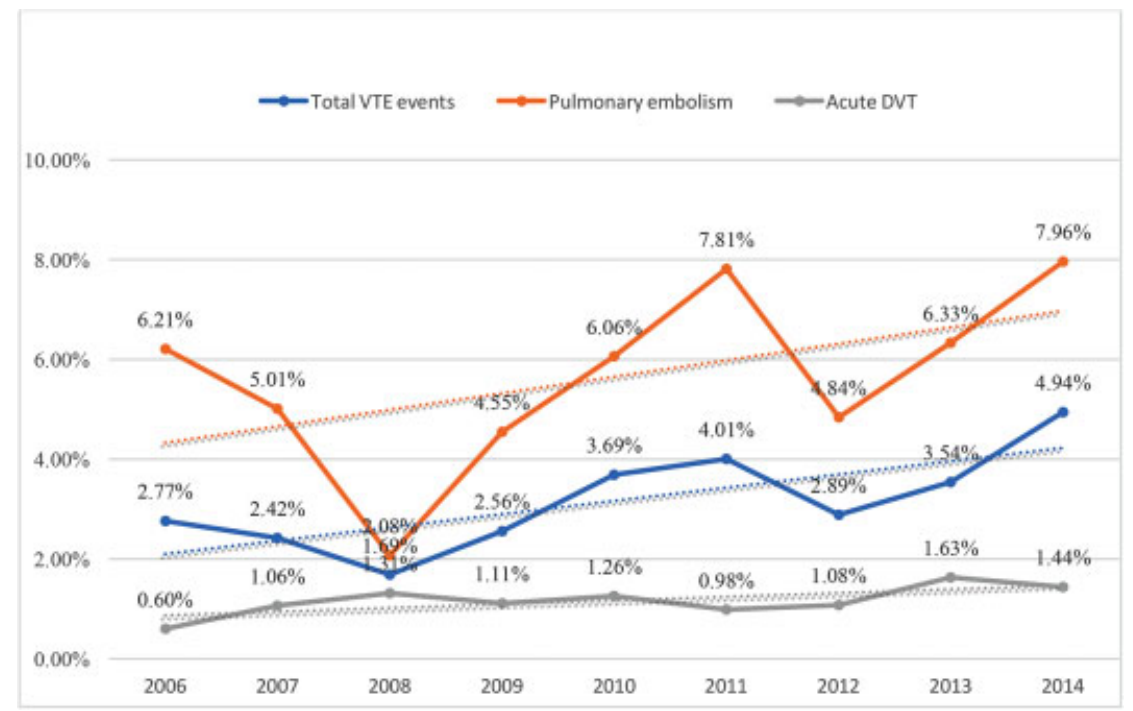

Fig. 2 Trends of in-hospital mortality of VTE-related hospitalizations. DVT, deep vein thrombosis; VTE, venous thromboembolism.

admissions, we abstracted 39,124 (3.7\%) VTE-related admissions. ET was the most frequently identified MPN from all VTE hospitalizations $(20,520 ; 52.4 \%)$ followed by PV $(13,057$; $33.3 \%)$ and PMF $(5,548 ; 14.1 \%)$.

The majority of patients in our cohort were 60 years or older, particularly in the PMF subgroup (89.9\%). Age is a wellrecognized risk factor for thrombosis in patients with MPN. For instance, the European Collaboration on Low-dose Aspirin in PV (ECLAP) study demonstrated that age over 65 years led to increased risk of a thromboembolic event in PV patients. ${ }^{12}$ Similarly, elderly patients with ET have an increased risk for VTE. Consequently, well-validated risk stratification models like the International Prognostic Scoring for Thrombosis in ET patients (IPSET) criteria incorporate age over 60 years as a criterion for prediction of thrombotic events. ${ }^{13}$

When we analyzed VTE hospitalizations by MPN tumor types, we observed a higher rate of VTE admissions in patients with PV compared with ET and PMF (4.2 vs. 3.5 vs. $3.2 \% ; p \leq 0.001$ ). The higher incidence of VTE in patients with PV compared with other MPN has been previously and extensively described. ${ }^{14}$ It is plausible that the higher incidence of VTE in patients with PV would lead to a higher rate of VTE-related hospitalizations when compared with other MPNs as observed in our study population. 


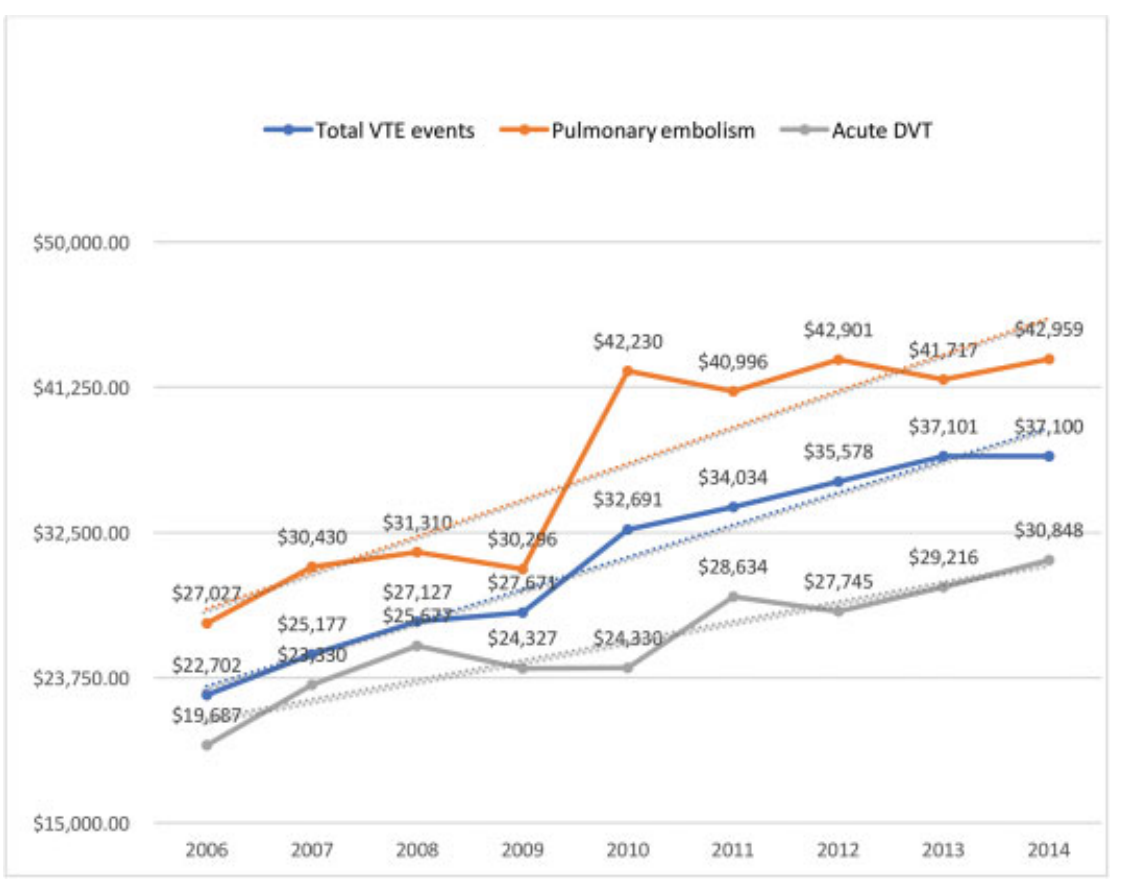

Fig. 3 Trends in total costs per VTE admission in U.S. dollars. DVT, deep vein thrombosis; VTE, venous thromboembolism.

When examining VTE subtypes in our cohort, DVT was more common in patients with PV ( $43.9 \%$ of VTE events in PV group), while PE was more common in ET patients (42.6\% of VTE events within ET group). Specific risk factors for development of PE in MPN patient have not been previously described and remain an area of investigation.

In our cohort, PMF patients had the highest rate of BCS compared with other MPN (PMF: $7.7 \%$ vs. PV: $4.4 \%$ vs. ET: $1.2 \%$; $p \leq 0.001$ ). Although the association of MPN to BCS is well known, PMF has been described as having a lower prevalence among BCS patients. For instance, in a recent meta-analysis of 1,062 patients with BCS, Smalberg et al reported the prevalence of PMF to be lowest (6.7\%; 95\% confidence interval [CI]: 32.349.5\%) when compared with PV (52.9\%; 95\% CI: 42.2-63.4\%) and ET (24.6\%; 95\% CI: $18-32.2 \%) .{ }^{15}$ The higher incidence of BCS in our cohort could be caused by a selection of a high-risk group of PMF patients with other concurrent tumor- and patientdependent VTE risk factors not included in the NIS database like JAK2V617F mutation burden. ${ }^{16}$ Furthermore, the higher rate of thrombocytopenia in PMF may have led to higher VTE hospitalization rate due to bleeding complications during anticoagulation therapy.

\section{Comparison of In-Patient Mortality Rates, Cost, and Length-of-Stay in MPN Patients with VTE Hospitalizations}

In our cohort, mortality was similar in VTE versus non-VTE groups ( 3.3 vs. $3.2 ; p=0.646$ ). In contrast, cancer-associated thrombosis has been linked to a poorer prognosis in hospitalized patients. For instance, in a cohort of 3,146,388 hospitalized patients with cancer, Lyman et al demonstrated a higher in-hospital mortality for patients with cancerrelated VTE (15 vs. 5.5\%) compared with non-cancer-related VTE. ${ }^{17}$ This difference may be explained by a more indolent course of MPNs compared with solid tumors included in other descriptive studies. Moreover, the presence of less severe forms of VTE (e.g., upper extremity DVT and lower extremity DVT) in our cohort could have contributed to comparable rates of mortality in the VTE- and non-VTErelated hospitalization groups.

In our study population, VTE-related admissions in MPN patients were associated with a higher cost (USD 31,549 vs. 28,426; $p=0.001$ ) and a longer LOS ( 6 vs. 5 days, $p \leq 0.001$ ), similar to findings of other descriptive studies. ${ }^{18}$ The higher costs are commonly due not only to anticoagulation therapy but also to diagnostic imaging studies and bleeding complications occurring in approximately $8 \%$ of all MPN patients. ${ }^{19}$

\section{Trends of Yearly Rates of VTE Hospitalizations in Patients with MPN}

We observed a decline in VTE-related admissions of MPN patients over the study period (2006: $3.94 \%$ vs. 2014 : $2.43 \%$; $p<0.001$ ). This is potentially explained by a more widespread use of risk-adapted strategies to decrease the risk of VTE in high-risk patients using antiplatelet drugs and cytoreductive agents. ${ }^{20,21}$ Moreover, changes in practice regarding outpatient management of DVT could have potentially reduced DVTrelated admissions throughout the study period.

Interestingly, we observed a trend toward an increase in incidence of PE-related admissions during the study period (2006: $1.1 \%$ vs. $2014: 1.49 \%, p<0.01$ ). This change may reflect the increased detection of PE since the widespread use of computed tomography angiography for diagnosis. ${ }^{22}$ However, it is still possible that there are other biological or environmental factors that predispose MPN patients to develop PE, particularly patients with ET.

The major strength of this study is that we used an NIS database. This allowed us to abstract a large cohort of patients 
with MPN and thus obtain robust estimations regarding outcomes of patients hospitalized for VTE. Limitations of the study include those inherent to retrospective studies and the absence of a marker of severity of VTE coded in NIS database, precluding our study from analyzing the impact of VTE severity on overall mortality, cost, and LOS in VTE hospitalizations. In addition, other factors like duration of MPN disease before occurrence of VTE, choice of anticoagulation, or use of prior cytoreductive therapy could not be obtained from the NIS database.

One limitation of our study is the inability to estimate the costs of care after hospitalization. It is unknown if the cost of care will eventually be similar in VTE- and non-VTE-related admissions after hospitalization. However, the focus of our study was to examine in-hospital outcomes to delineate strategies that would allow for the prevention of VTE in patients with MPN which, in turn, would improve resource allocation for the care of this patient population.

Another limitation of our study is that the exact timing of VTE in the NIS database cannot be determined. Nonetheless, we accounted for this limitation by selecting patients with a VTE event on the principal or the top-two secondary diagnosis, which can be reliably assumed to be acute and a main concern during hospitalization. This allowed an accurate selection of patients with a VTE-related hospitalization and enabled us to provide an estimate of their outcomes.

In conclusion, VTE-related admissions in patients with MPN were associated with higher costs and prolonged hospitalization. Furthermore, there is a decline in VTE-related admissions of MPN patients, although yearly rates of PE-related admissions have increased from 2006 to 2014, regardless of the type of MPNs. Further refining our risk-stratification strategy to include clinical, cytogenetic, and biological data may assist in preventing VTE in high-risk patients and decrease VTE-related mortality and cost burden in patients with MPNs.

\section{Conflict of Interest}

None declared.

\section{Acknowledgments}

All authors contributed equally to the development of this manuscript and did not receive any compensation related to the development of this article. This study was presented in part as Abstract e19030 at the 54th Annual Meeting of the American Society of Clinical Oncology, June 1-5, 2018, Chicago, Illinois, United States.

\section{References}

1 Johansson P. Epidemiology of the myeloproliferative disorders polycythemia vera and essential thrombocythemia. Semin Thromb Hemost 2006;32(03):171-173

2 Fabris F, Randi ML. Essential thrombocythemia: past and present. Intern Emerg Med 2009;4(05):381-388

3 Tafur AJ, Kalsi H, Wysokinski WE, et al. The association of active cancer with venous thromboembolism location: a populationbased study. Mayo Clin Proc 2011;86(01):25-30

4 Barbui T, De Stefano V. Management of venous thromboembolism in myeloproliferative neoplasms. Curr Opin Hematol 2017;24 (02):108-114
5 De Stefano V, Ruggeri M, Cervantes F, et al. High rate of recurrent venous thromboembolism in patients with myeloproliferative neoplasms and effect of prophylaxis with vitamin $\mathrm{K}$ antagonists. Leukemia 2016;30(10):2032-2038

6 Tefferi A, Barbui T. Polycythemia vera and essential thrombocythemia: 2015 update on diagnosis, risk-stratification and management. Am J Hematol 2015;90(02):162-173

7 Khorana AA, Francis CW, Culakova E, Kuderer NM, Lyman GH. Thromboembolism is a leading cause of death in cancer patients receiving outpatient chemotherapy. J Thromb Haemost 2007;5 (03):632-634

8 Sørensen HT, Mellemkjaer L, Olsen JH, Baron JA. Prognosis of cancers associated with venous thromboembolism. N Engl J Med 2000;343(25):1846-1850

9 Puurunen MK, Gona PN, Larson MG, Murabito JM, Magnani JW, O'Donnell CJ. Epidemiology of venous thromboembolism in the Framingham Heart Study. Thromb Res 2016;145:27-33

10 Grosse SD, Nelson RE, Nyarko KA, Richardson LC, Raskob GE. The economic burden of incident venous thromboembolism in the United States: a review of estimated attributable healthcare costs. Thromb Res 2016;137:3-10

11 Barco S, Woersching AL, Spyropoulos AC, Piovella F, Mahan CE. European Union-28: an annualised cost-of-illness model for venous thromboembolism. Thromb Haemost 2016;115(04):800-808

12 Marchioli R, Finazzi G, Landolfi R, et al. Vascular and neoplastic risk in a large cohort of patients with polycythemia vera. J Clin Oncol 2005;23(10):2224-2232

13 Barbui T, Finazzi G, Carobbio A, et al. Development and validation of an International Prognostic Score of thrombosis in World Health Organization-essential thrombocythemia (IPSET-thrombosis). Blood 2012;120(26):5128-5133, quiz 5252

14 Kreher S, Ochsenreither S, Trappe RU, et al; Haemostasis Working Party of the German Society of Hematology and Oncology; Austrian Society of Hematology and Oncology; Society of Thrombosis and Haemostasis Research. Prophylaxis and management of venous thromboembolism in patients with myeloproliferative neoplasms: consensus statement of the Haemostasis Working Party of the German Society of Hematology and Oncology (DGHO), the Austrian Society of Hematology and Oncology (ÖGHO) and Society of Thrombosis and Haemostasis Research (GTH e.V.). Ann Hematol 2014;93(12):1953-1963

15 Smalberg JH, Arends LR, Valla DC, Kiladjian JJ, Janssen HL, Leebeek FW. Myeloproliferative neoplasms in Budd-Chiari syndrome and portal vein thrombosis: a meta-analysis. Blood 2012;120(25):4921-4928

16 How J, Zhou A, Oh ST. Splanchnic vein thrombosis in myeloproliferative neoplasms: pathophysiology and molecular mechanisms of disease. Ther Adv Hematol 2017;8(03):107-118

17 Lyman GH, Culakova E, Poniewierski MS, Kuderer NM. Morbidity, mortality and costs associated with venous thromboembolism in hospitalized patients with cancer. Thromb Res 2018;164(Suppl 1): S112-S118

18 Khorana AA, Dalal MR, Lin J, Connolly GC. Health care costs associated with venous thromboembolism in selected high-risk ambulatory patients with solid tumors undergoing chemotherapy in the United States. Clinicoecon Outcomes Res 2013;5:101-108

19 Kaifie A, Kirschner M, Wolf D, et al; Study Alliance Leukemia (SAL). Bleeding, thrombosis, and anticoagulation in myeloproliferative neoplasms (MPN): analysis from the German SAL-MPN-registry. J Hematol Oncol 2016;9:18

20 Tefferi A, Vannucchi AM, Barbui T. Polycythemia vera treatment algorithm 2018. Blood Cancer J 2018;8(01):3

21 Tefferi A, Vannucchi AM, Barbui T. Essential thrombocythemia treatment algorithm 2018. Blood Cancer J 2018;8(01):2

22 Wiener RS, Schwartz LM, Woloshin S; RS W. Time trends in pulmonary embolism in the United States: evidence of overdiagnosis. Arch Intern Med 2011;171(09):831-837 